\title{
Arterial Stiffness, Kidney Function, and Chronic Kidney Disease Progression
}

\author{
Raymond R. Townsend ${ }^{a} \quad$ Hirofumi Tomiyamab \\ a Perelman School of Medicine, University of Pennsylvania, Philadelphia, Pa., USA; \\ bSecond Department of Internal Medicine, Tokyo Medical University, Tokyo, Japan
}

\section{Key Words}

Pulse wave velocity - Central aortic pressure - Augmentation index - Chronic kidney disease .

Arterial stiffness · End-stage kidney disease

\begin{abstract}
Arterial stiffness can nowadays be measured easily and noninvasively around the globe. Although well established as an independent predictor of cardiovascular events, less is known about the role of arterial stiffness in the progressive loss of kidney function once chronic kidney disease (CKD) is established. In addition to measures of arterial stiffness, a number of devices now noninvasively record the pulse profile from sites such as the radial artery and, using internal algorithms, are able to estimate central pressure profiles. Although these devices have generated much data on the prediction of cardiovascular events, e.g. measures of arterial stiffness, there is much less known about the predictive utility of these measures in CKD progression. In this review, we cover approaches to arterial stiffness as measured by pulse wave velocity and discuss measures of the systolic and diastolic contour of the pulse waveform vis-à-vis their relationship to declines in kidney function over time. We restrict our coverage to studies that have longitudinal data, but we also include a table of studies, which, to our knowledge, have only published cross-sectional data at this time.
\end{abstract}

(c) 2013 S. Karger AG, Basel

\section{Introduction}

Brachial blood pressure has long been known to be a determinant of kidney function decline, and the reader is referred to recent standard reviews on this aspect [1]. In this review, we pursue newer and somewhat more innovative approaches to arterial function beyond blood pressure, namely arterial stiffness as measured by pulse wave velocity (PWV), and

Raymond R. Townsend, MD

University of Pennsylvania

3400 Spruce Street, 122 Founders Building

Philadelphia, PA 19104 (USA)

E-Mail townsend@mail.med.upenn.edu 
Townsend et al.: Arterial Stiffness, Kidney Function, and Chronic Kidney Disease Progression

Table 1. Studies reporting longitudinal and cross-sectional data

\begin{tabular}{|c|c|c|c|c|}
\hline Cohort & $\begin{array}{l}\text { Patients } \\
\text { (\% women) }\end{array}$ & PWV & $\begin{array}{l}\text { Pulse contour } \\
\text { analysis }\end{array}$ & Principal findings \\
\hline Hoorn $[22]^{\mathrm{a}}$ & $256(47 \%)$ & Tonometry & Tonometry & $\begin{array}{l}\text { Central arterial stiffness not independently asso- } \\
\text { ciated with reduced kidney function }\end{array}$ \\
\hline REN-Art $[44]^{\mathrm{a}}$ & $273(36 \%)$ & $\begin{array}{l}\text { Mechano- } \\
\text { transducer }\end{array}$ & & $\begin{array}{l}\text { Arterial stiffness and carotid distensibility related } \\
\text { to GFR in CKD }\end{array}$ \\
\hline Nephrotest [21] & $180(26 \%)$ & $\begin{array}{l}\text { Mechano- } \\
\text { transducer }\end{array}$ & Tonometry & $\begin{array}{l}\text { Aortic PWV not independently predictive of CKD } \\
\text { progression; carotid circumferential wall stress } \\
\text { predictive of CKD progression and } \\
\text { development of ESKD }\end{array}$ \\
\hline Derby [36] & $35(40 \%)$ & Tonometry & Tonometry & $\begin{array}{l}\text { Both aortic PWV and central augmentation index } \\
\text { predicted development of ESKD in patients with } \\
\text { advanced CKD }\end{array}$ \\
\hline Sussex [20] & $133(23 \%)$ & $\begin{array}{l}\text { Mechano- } \\
\text { transducer }\end{array}$ & & $\begin{array}{l}\text { Aortic stiffness independently predicted loss } \\
\text { of kidney function in stage } 3 \text { and stage } 4 \text { CKD } \\
\text { patients }\end{array}$ \\
\hline Saitama [35] & $99(33 \%)$ & & Oscillometry & $\begin{array}{l}\text { Higher radial augmentation index predicted rate } \\
\text { of decline in creatinine clearance }\end{array}$ \\
\hline Tokyo DM Study [18] & $461(47 \%)$ & $\begin{array}{l}\text { Mechano- } \\
\text { transducer }\end{array}$ & & $\begin{array}{l}\text { Higher carotid-femoral PWV predicted change in } \\
\text { albuminuria category (normal to microalbu- } \\
\text { minuria to macroalbuminuria) }\end{array}$ \\
\hline Edinburgh [45] & $113(32 \%)$ & Tonometry & Tonometry & $\begin{array}{l}\text { Augmentation index not associated with CKD } \\
\text { stage; blood pressure and not arterial stiffness } \\
\text { associated with CKD stage in a CKD cohort without } \\
\text { diabetes mellitus and with minimal comorbidity }\end{array}$ \\
\hline Tokyo Worksite [15] & $2,053(19 \%)$ & Oscillometry & & baPWV predicted incident CKD \\
\hline CRIC [26] & $2,564(43 \%)$ & Tonometry & Tonometry & $\begin{array}{l}\text { PWV + pulse pressure (central or brachial) } \\
\text { predicted ESKD and CKD progression }\end{array}$ \\
\hline MESA [34] & $4,853(51 \%)$ & & Tonometry & $\begin{array}{l}\text { Large- and small-vessel elasticity predictive of } \\
\text { rate of kidney function decline in subjects with an } \\
\text { eGFR }>60 \mathrm{ml} / \mathrm{min} / 1.73 \mathrm{~m}^{2} \text { at enrollment }\end{array}$ \\
\hline
\end{tabular}

${ }^{\text {a }}$ Cross-sectional data.

discuss measures of the systolic and diastolic contour of the pulse waveform vis-à-vis their relationship to declines in kidney function over time. In the main body of this paper, we restrict our coverage to studies that report longitudinal data. However, in addition to these studies, table 1 includes investigations, which, to our knowledge, have only published crosssectional data at this time.

\section{Arterial Stiffness in Chronic Kidney Disease}

The incorporation of arterial stiffness measurements into longitudinal cohort studies has yielded insight into the role of pulse transmission characteristics as a predictor of important vascular outcomes [2]. Arterial stiffness is reflected by the velocity of the pulse wave in a segment of the circulation. Detecting the pulse wave noninvasively is now possible by reliable ultrasound, mechanotransductive, tonometric and oscillometric methods, and the publi- 
Townsend et al.: Arterial Stiffness, Kidney Function, and Chronic Kidney Disease Progression

cation of age-related reference values has helped to standardize the measurement of arterial stiffness [3]. Although well established as a predictor of cardiovascular and cerebrovascular end points [2, 4-6], much less is known about the role of arterial stiffness in chronic kidney disease (CKD) progression. In this review, we address what is known about arterial stiffness in patients with CKD and consider evidence that arterial stiffness is involved in CKD progression. Finally, we speculate on mechanisms that could explain the relationship between arterial stiffness and CKD progression and on areas that we think are important for further research.

One might wonder why arterial stiffness would be important in CKD. Interestingly, the brain and the kidneys, though at opposite 'ends' of the aorta, share at least one thing in common, namely a blood flow relative to the organ size that has been described as 'torrential' [7]. Both organs have a very low resistance to blood flow and are thus peculiarly susceptible to the barotrauma of the pulse wave when the force and velocity of the pulse wave are increased from aging and disease.

One of the first studies of arterial stiffness to specifically evaluate the cross-sectional relationship between stiffness and CKD was undertaken by Mourad et al. [8]. In a study of 1,290 subjects with a serum creatinine of $<130 \mu \mathrm{mol} / \mathrm{l}$ (or $1.5 \mathrm{mg} / \mathrm{dl}$ ) they noted, particularly in subjects $<55$ years old, that in the lowest tertile of kidney function, there was an inverse relationship between creatinine clearance and the aortic PWV. Their observation expanded our understanding of stiffness by pointing out that central artery compliance is associated with reduced creatinine clearance in patients with mild-to-moderate renal insufficiency. Importantly, the authors noted that kidney alterations affect not only the small but also the large arteries, independently of age, blood pressure, and standard cardiovascular risk factors.

\section{Studies of Arterial Stiffness and CKD Progression}

Arterial stiffness can be measured noninvasively in humans through ultrasonographic, magnetic resonance, oscillometric, tonometric, or mechanotransductive detection of the arterial pulse at different places in the arterial circulation. Although ultrasonographic and magnetic resonance imaging have been used in longitudinal cohort studies where cardiovascular outcomes were the primary end points [9], they have not been widely used in cohorts where kidney function is the outcome, and thus they are not discussed further here.

In Asian studies, a commonly used method of determining arterial stiffness involves simultaneous oscillometric measurement of the brachial and ankle PWV (baPWV). Although PWV can be measured in any arterial segment between two pulse wave-palpable regions [10], the assessment of central arterial stiffness rather than that of peripheral arterial stiffness is more relevant to cardiovascular risk stratification [11]. Though the carotid-femoral PWV is often considered the gold standard for the assessment of central arterial stiffness [12], a high skill level and exposure of the inguinal region are required for its measurement. In Japan, the baPWV is measured, and this method is simple enough for application in clinical practice, just involving wrapping of a pressure cuff around each of the four extremities [13]. One of the limitations of baPWV measurement is that this parameter reflects not only elastic arterial stiffness but also muscular arterial stiffness [13]. Even so, the baPWV has been demonstrated to show a close correlation to the aortic PWV [14] and carotid-femoral PWV [13], and a recent meta-analysis demonstrated that the baPWV is an independent marker to predict future cardiovascular events [14].

Several cross-sectional studies have demonstrated that baPWV is associated with estimated glomerular filtration rate (eGFR) [13]. Furthermore, recently, we conducted a prospective study in 2,053 Japanese employees with an eGFR $\geq 60 \mathrm{ml} / \mathrm{min} / 1.73 \mathrm{~m}^{2}$ without proteinuria at the start using the Omron device. In this study, after adjusting for confounding variables, every $\mathrm{m} / \mathrm{s}$ higher baPWV was associated with a $36 \%$ increased odds (95\% CI 1.09- 
Townsend et al.: Arterial Stiffness, Kidney Function, and Chronic Kidney Disease Progression

1.70; $\mathrm{p}<0.01$ ) for a development of an eGFR $<60 \mathrm{ml} / \mathrm{min} / 1.73 \mathrm{~m}^{2}$ at the end of a 5- to 6-year follow-up [15]. Similar findings were also confirmed in subjects with CKD stages 3-5 by Chen et al. [16]. Thus, baPWV may be a marker to predict the progression of renal function decline in subjects with not only preserved renal function but also CKD.

In the afore-mentioned study by Chen et al. [16], a higher baPWV was also associated with death in 145 patients with CKD stages 3-5. In the measurement of baPWV, the anklebrachial pressure index (ABI) can be obtained simultaneously. Kitahara et al. [17] reported that ABI showed strong power in predicting the mortality of 785 hemodialysis patients. Additionally, baPWV was useful to identify a high-risk population in patients with an ABI $>0.9$ [17]. Thus, baPWV is applicable to predict future cardiovascular events in subjects with CKD.

In another study from Tokyo [18], the investigators used the transducers in the Fukuda Denshi PWV-200 (oscillometric) device to record the carotid and femoral pulses simultaneously in 461 Japanese diabetics with normal urine albumin excretion $(n=339)$ or with microalbuminuria $(\mathrm{n}=122)$. During the 6-year follow-up, 85 subjects changed their category (from normal to microalbuminuria: $\mathrm{n}=56$, or from microalbuminuria to macroalbuminuria: $\mathrm{n}=29$ ). Using the median value of $9.1 \mathrm{~m} / \mathrm{s}$, patients above the median were more likely to change their albuminuria category compared with those below the median.

In European studies of kidney function decline, arterial stiffness is usually measured as carotid-femoral PWV using tonometry [19]. In the Derby (UK) study [36], 35 patients with advanced CKD (eGFR $13.4 \mathrm{ml} / \mathrm{min} / 1.73 \mathrm{~m}^{2}$ ) who were followed for an average of 1 year were studied using the Sphygmocor (tonometric) device. Twenty-two of the $35(63 \%)$ patients began dialysis during the 1-year follow-up. Using proportional hazards analysis, the investigators observed that proteinuria had the highest hazard ratio for progression to end-stage kidney disease (ESKD), but PWV was the second strongest predictor (HR 1.3, 95\% CI 1.071.60). In East Sussex, the investigators enrolled 133 subjects with stage 3 (eGFR 30-59 ml/ $\mathrm{min} / 1.73 \mathrm{~m}^{2}$ ) and stage 4 CKD (eGFR $15-29 \mathrm{ml} / \mathrm{min} / 1.73 \mathrm{~m}^{2}$ ) and performed measures of aortic PWV using the Complior (mechanotransductive) device [20]. In their multivariable adjusted analysis, the authors showed that PWV, blood pressure, and proteinuria were independently predictive of a $25 \%$ reduction in kidney function or the need for renal replacement therapy.

The NephroTest study enrolled 180 patients with an average eGFR of $32 \mathrm{ml} / \mathrm{min} / 1.73 \mathrm{~m}^{2}$ from the Paris area and used the Complior device to measure the carotid-femoral PWV as well as the Sphygmocor system to record radial and carotid waveforms [21]. This study found that aortic stiffness did not change appreciably during follow-up, whereas carotid stiffness did. The carotid distensibility predicted the decline in eGFR over time independently of standard factors such as blood pressure and proteinuria. The aortic PWV did not appear to influence the progression of CKD. In this study, the carotid intima-media thickness was measured, and the results showed that the carotid wall thickness actually decreased over time, which, in turn, increased the wall stress. The expected response would be an increase in wall thickening to adapt to the pressure load. The thinning process actually boded poorly for the patients' kidney function, and the authors pointed out that similar findings were presented in the Hoorn study [22].

The American Chronic Renal Insufficiency Cohort (CRIC) study represents a large, ethnically diverse cohort of patients with CKD [23]. Approximately half have diabetes, and the cohort has now been followed for a mean of $>5$ years. The average eGFR in the CRIC cohort at enrollment was $43.4 \mathrm{ml} / \mathrm{min} / 1.73 \mathrm{~m}^{2}$. Measures of PWV (carotid-femoral tonometry) and pulse wave analysis (radial tonometry) were incorporated into the CRIC protocol beginning with the 2nd year of follow-up. Only the cross-sectional data have been fully published [24]. These data from 2,564 participants indicate that diabetes, blood glucose levels, age, and black 
Townsend et al.: Arterial Stiffness, Kidney Function, and Chronic Kidney Disease Progression

race independently and positively predicted aortic PWV. Female gender and eGFR were independently and negatively predictive of PWV. The central aortic blood pressures in the CRIC study were estimated from radial tonometry. Most of the variability in central aortic pulse pressure (84\%) was explained by the brachial pulse pressure [25]. Age, male gender, heart rate, and the presence of diabetes (but not kidney function) contributed independently to the residual variability. The interaction of PWV with pulse pressure (brachial or central) on kidney function has been presented in abstract form [26]. In this abstract, the incidence of ESKD or the doubling of creatinine, which is measured yearly in the CRIC study and expressed using the creatinine-based MDRD equation [27], was approximately 3 - to 5-fold higher in the highest tertiles of PWV and either brachial or central pulse pressure when compared with the lowest tertiles of PWV and pulse pressure.

\section{Pulse Contour Analysis and CKD}

Analysis of the pulse waveform has proven useful to understand the cardiovascular risk that may not be evident from the blood pressure alone [28, 29]. A recent meta-analysis [30] showed that the augmentation index had a predictive value for future cardiovascular events in 5,648 subjects followed for nearly 4 years. Although not all studies have found pulse wave contour to be useful [31], the general impression is that there is information contained in the waveform that reveals something about how pulse waves travel and are reflected backwards in the circulation, and how this may have consequences for target organ damage. In some cases, it requires going 'outside the box' as we did recently by analyzing the radial pulse waveforms to tease out the forward and backward traveling waves in the Multi-Ethnic Study of Atherosclerosis (MESA) trial, in which it was shown that the backward traveling waveform contained information that strongly and independently (of blood pressure) predicted the occurrence of heart failure in this cohort [32]. The importance of such findings is that the backward traveling waveform is modifiable by drug therapy, and our results could easily be tested by an intervention study.

Although most studies of pulse contour analyze the systolic component, at least one device analyzes the diastolic component [33]. There are fewer studies using diastolic contour analysis when compared with systolic, and we could only find one prospective study that examined CKD progression using this approach [34].

\section{Studies of Pulse Wave Contour and CKD Progression: Systolic Contour Analyses}

An Asian study of 99 patients with CKD collected radial artery waveforms using the Omron HEM9010AI (oscillometric) device [35]. Forty-four of the subjects were then followed prospectively for at least 1 year. Higher values for the radial augmentation index were associated with a more rapid decline in creatinine clearance during follow-up. In a multiple regression analysis of factors that influenced the annual change in creatinine clearance, only proteinuria and the augmentation index demonstrated significant associations with this outcome. Systolic and diastolic pressure, heart rate, and age were not significantly related.

With regard to European studies of pulse wave contour and CKD progression, we return to the Derby (UK) group [20], which studied 35 patients with advanced CKD (eGFR $13.4 \mathrm{ml}$ / $\min / 1.73 \mathrm{~m}^{2}$ ) using the Sphygmocor device to estimate the central augmentation index. Again, using proportional hazards analysis, the investigators observed that, in addition to proteinuria and PWV, the central augmentation index was also predictive (HR 1.08, 95\% CI 1.04-1.14) of progression to ESKD requiring dialysis [36]. 
Townsend et al.: Arterial Stiffness, Kidney Function, and Chronic Kidney Disease Progression

Studies of Pulse Wave Contour and CKD Progression: Diastolic Contour Analysis

Using the HDI (tonometric) device that records the radial arterial waveform and estimates large- and small-vessel elasticity, Peralta et al. [34] studied subjects enrolled in the US MESA trial, a longitudinal cohort of four ethnicities (white, black, Asian, and Hispanic) free of cardiovascular disease at baseline. In a subset of 4,853 (of the 6,814 participants enrolled in MESA), with an initial eGFR $>60 \mathrm{ml} / \mathrm{min} / 1.73 \mathrm{~m}^{2}$, they evaluated the brachial pulse pressure, vessel elasticity, and flow-mediated vasodilation, and found that the brachial pulse pressure and lower values for large (C1) and small (C2) arterial elasticity were linearly predictive of the rate of decline in kidney function; however, flow-mediated dilation was not [37].

Why Does Arterial Stiffness Feature so Prominently in CKD?

A full discussion of mechanisms by which arterial stiffness is so common in CKD is beyond the scope of this review. Suffice it to say that we think that CKD, and one of the most common forms of CKD - diabetic nephropathy, basically are forms of accelerated aging. It makes some sense then that vascular calcification, inflammation, oxidative stress, abnormalities in tissue metalloproteinases, accumulating environmental exposures such as cigarette smoke, vulnerability to salt-related increases in pressure, and likely a host of other factors contribute to the high prevalence of arterial stiffness in CKD and ESKD. For an excellent recent review of these mechanisms, refer to Briet et al. [37].

Why Pulse Wave Velocity and Pulse Contour Are Important to Kidney Circulation

The kidney, unlike most organs except for the brain, has a remarkably low systemic vascular resistance [7]. As a result, the pulse wave 'penetrates' much more deeply into the microcirculation of the kidney; thus, the delicate circulation of the glomerulus is placed at risk when the afferent arteriole fails to function as a 'gatekeeper'. This seems most relevant to systolic pressure, as shown by the elegant in vivo work by Loutzenhiser et al. [38], Bidani et al. [39], and Griffin [40]. Their collective research indicates that the afferent arteriole responds very quickly with constriction to alterations that increase systolic pressure, with virtually no response if only diastolic pressure is raised [41]. When we consider that many forms of progressive kidney disease, such as diabetes and hypertension, are characterized by nonobstructing afferent arteriolar hyalinosis and enlargement, it seems plausible that a greater systolic impact (i.e. more pulsatility) driven at a higher velocity (from greater arterial stiffness) transmitted into the glomerulus with each heartbeat would be poorly tolerated over time. Arguably, a greater understanding of myogenic responses and their failure is a fruitful area to investigate in order to further understand the loss of kidney function in CKD [42]. The work of Hill et al. [43] makes this point well, showing that enlargement of the afferent arteriole from nonobstructing lesions such as hyaline deposition is associated with glomerular enlargement and focal sclerotic lesions.

We hope that, as observations continue to accumulate in longitudinal cohorts such as those listed in table 1 and others we may have missed, a clearer understanding will emerge of not only how these tools (stiffness measures and contour analysis) can be useful for predicting kidney function loss and/or CKD progression; even more importantly, the use of these measures to guide or improve our lifestyle as well as the use of drug interventions to slow or even arrest the progressive loss of precious nephrons in our patients remain the most needed aspects of this field.

\section{Acknowledgements}

This work was supported by NIH grant R01DK067390. 
Townsend et al.: Arterial Stiffness, Kidney Function, and Chronic Kidney Disease Progression

\section{References}

- 1 Lindeman RD, Tobin JD, Shock NW: Association between blood pressure and the rate of decline in renal function with age. Kidney Int 1984;26:861-868.

- 2 O’Rourke MF, Mancia G: Arterial stiffness. J Hypertens 1999;17:1-4.

- 3 Reference Values for Arterial Stiffness' Collaboration: Determinants of pulse wave velocity in healthy people and in the presence of cardiovascular risk factors: 'establishing normal and reference values'. Eur Heart J 2010;31:2338-2350.

4 Meaume S, Benetos A, Henry OF, Rudnichi A, Safar ME: Aortic pulse wave velocity predicts cardiovascular mortality in subjects $>70$ years of age. Arterioscler Thromb Vasc Biol 2001;21:2046-2050.

$\checkmark 5$ Avolio AP, Deng FQ, Li WQ, Luo YF, Huang ZD, Xing LF, O’Rourke MF: Effects of aging on arterial distensibility in populations with high and low prevalence of hypertension: comparison between urban and rural communities in China. Circulation 1985;71:202-210.

- 6 Blacher J, Guerin AP, Pannier B, Marchais SJ, Safar ME, London GM: Impact of aortic stiffness on survival in end-stage renal disease. Circulation 1999;99:2434-2439.

7 O'Rourke MF, Safar ME: Relationship between aortic stiffening and microvascular disease in brain and kidney: cause and logic of therapy. Hypertension 2005;46:200-204.

- 8 Mourad JJ, Pannier B, Blacher J, Rudnichi A, Benetos A, London GM, Safar ME: Creatinine clearance, pulse wave velocity, carotid compliance and essential hypertension. Kidney Int 2001;59:1834-1841.

9 Vlachopoulos C, Aznaouridis K, Stefanadis C: Prediction of cardiovascular events and all-cause mortality with arterial stiffness: a systematic review and meta-analysis. J Am Coll Cardiol 2010;55:1318-1327.

10 Asmar R: Pulse wave velocity. Principle and measurement; in Asmar R (ed): Arterial Stiffness and Pulse Wave Velocity, ed 1. Amsterdam, Elsevier, 1999.

11 Safar ME, Levy BI, Struijker-Boudier H: Current perspectives on arterial stiffness and pulse pressure in hypertension and cardiovascular diseases. Circulation 2003;107:2864-2869.

12 Mancia G, De Backer G, Dominiczak A, et al: 2007 Guidelines for the Management of Arterial Hypertension: The Task Force for the Management of Arterial Hypertension of the European Society of Hypertension (ESH) and of the European Society of Cardiology (ESC). J Hypertens 2007;25:1105-1187.

13 Tomiyama H, Yamashina A: Non-invasive vascular function tests: their pathophysiological background and clinical application. Circ J 2010;74:24-33.

14 Vlachopoulos C, Aznaouridis K, Terentes-Printzios D, Ioakeimidis N, Stefanadis C: Prediction of cardiovascular events and all-cause mortality with brachial-ankle elasticity index: a systematic review and meta-analysis. Hypertension 2012;60:556-562.

-15 Tomiyama H, Tanaka H, Hashimoto H, Matsumoto C, Odaira M, Yamada J, Yoshida M, Shiina K, Nagata M, Yamashina A: Arterial stiffness and declines in individuals with normal renal function/early chronic kidney disease. Atherosclerosis 2010;212:345-350.

16 Chen SC, Chang JM, Liu WC, Tsai YC, Tsai JC, Hsu PC, Lin TH, Lin MY, Su HM, Hwang SJ, Chen HC: Brachial-ankle pulse wave velocity and rate of renal function decline and mortality in chronic kidney disease. Clin J Am Soc Nephrol 2011;6:724-732.

17 Kitahara T, Ono K, Tsuchida A, Kawai H, Shinohara M, Ishii Y, Koyanagi H, Noguchi T, Matsumoto T, Sekihara T, Watanabe Y, Kanai H, Ishida H, Nojima Y: Impact of brachial-ankle pulse wave velocity and ankle-brachial blood pressure index on mortality in hemodialysis patients. Am J Kidney Dis 2005;46:688-696.

18 Bouchi R, Babazono T, Mugishima M, Yoshida N, Nyumura I, Toya K, Hanai K, Tanaka N, Ishii A, Uchigata Y, Iwamoto Y: Arterial stiffness is associated with incident albuminuria and decreased glomerular filtration rate in type 2 diabetic patients. Diabetes Care 2011;34:2570-2575

19 Laurent S, Cockcroft J, Van Bortel L, Boutouyrie P, Giannattasio C, Hayoz D, Pannier B, Vlachopoulos C, Wilkinson I, Struijker-Boudier H: Expert consensus document on arterial stiffness: methodological issues and clinical applications. Eur Heart J 2006;27:2588-2605.

20 Ford ML, Tomlinson LA, Chapman TP, Rajkumar C, Holt SG: Aortic stiffness is independently associated with rate of renal function decline in chronic kidney disease stages 3 and 4. Hypertension 2010;55:1110-1115.

-21 Briet M, Collin C, Karras A, Laurent S, Bozec E, Jacquot C, Stengel B, Houillier P, Froissart M, Boutouyrie P: Arterial remodeling associates with CKD progression. J Am Soc Nephrol 2011;22:967-974.

-22 Hermans MM, Henry R, Dekker JM, Kooman JP, Kostense PJ, Nijpels G, Heine RJ, Stehouwer CD: Estimated glomerular filtration rate and urinary albumin excretion are independently associated with greater arterial stiffness: the Hoorn Study. J Am Soc Nephrol 2007;18:1942-1952.

-23 Lash JP, Go AS, Appel LJ, He J, Ojo A, Rahman M, Townsend RR, Xie D, Cifelli D, Cohan J, Fink JC, Fischer MJ, Gadegbeku C, Hamm LL, Kusek JW, Landis JR, Narva A, Robinson N, Teal V, Feldman HI, Chronic Renal Insufficiency Cohort (CRIC) Study Group: Chronic Renal Insufficiency Cohort (CRIC) Study: baseline characteristics and associations with kidney function. Clin J Am Soc Nephrol 2009;4:1302-1311.

24 Townsend RR, Wimmer NJ, Chirinos JA, Parsa A, Weir M, Perumal K, Lash JP, Chen J, Steigerwalt SP, Flack J, Go AS, Rafey M, Rahman M, Sheridan A, Gadegbeku CA, Robinson NA, Joffe M: Aortic PWV in chronic kidney disease: a CRIC ancillary study. Am J Hypertens 2010;23:282-289.

25 Townsend RR, Chirinos JA, Parsa A, Weir MA, Sozio SM, Lash JP, Chen J, Steigerwalt SP, Go AS, Hsu CY, Rafey M, Wright JT Jr, Duckworth MJ, Gadegbeku CA, Joffe MP: Central pulse pressure in chronic kidney disease: a chronic renal insufficiency cohort ancillary study. Hypertension 2010;56:518-524. 
Townsend et al.: Arterial Stiffness, Kidney Function, and Chronic Kidney Disease Progression

-26 Townsend RR, Chirinos JA, Sozio SM, Chen J, Rafey M, Joffe MP, Weir MA, Duckworth MJ: Comparison of standard blood pressure, pulse wave velocity and central hemodynamics in CKD progression: A CRIC ancillary study. Hypertension 2010;56:article e68.

27 Levey AS, Coresh J, Greene T, Stevens LA, Zhang YL, Hendriksen S, Kusek JW, Van Lente F: Using standardized serum creatinine values in the modification of diet in renal disease study equation for estimating glomerular filtration rate. Ann Intern Med 2006;145:247-254.

28 Townsend RR: Analyzing the peripheral arterial pulse waveforms: narrowing the gap between blood pressure and outcomes. Curr Opin Nephrol Hypertens 2007;16:261-266.

29 Townsend RR, Roman MJ, Najjar SS, Cockcroft JR, Feig PU, Stockbridge NL: Central blood pressure measurements - an opportunity for efficacy and safety in drug development? J Am Soc Hypertens 2010;4:211-214.

30 Vlachopoulos C, Aznaouridis K, O’Rourke MF, Safar ME, Baou K, Stefanadis C: Prediction of cardiovascular events and all-cause mortality with central haemodynamics: a systematic review and meta-analysis. Eur Heart J 2010;31:1819-1822.

-31 Mitchell GF, Hwang SJ, Vasan RS, Larson MG, Pencina MJ, Hamburg NM, Vita JA, Levy D, Benjamin EJ: Arterial stiffness and cardiovascular events: the Framingham Heart Study. Circulation 2010;121:505-511.

-32 Chirinos JA, Kips JG, Jacobs DR Jr, Brumback L, Duprez DA, Kronmal R, Bluemke DA, Townsend RR, Vermeersch S, Segers P: Arterial wave reflections and incident cardiovascular events and heart failure: MESA (Multiethnic Study of Atherosclerosis). J Am Coll Cardiol 2012;60:2170-2177.

-33 Cohn JN, Finkelstein S, McVeigh G, Morgan D, LeMay L, Robinson J, Mock J: Noninvasive pulse wave analysis for the early detection of vascular disease. Hypertension 1995;26:503-508.

-34 Peralta CA, Jacobs DR Jr, Katz R, Ix JH, Madero M, Duprez DA, Sarnak MJ, Criqui MH, Kramer HJ, Palmas W, Herrington D, Shlipak MG: Association of pulse pressure, arterial elasticity, and endothelial function with kidney function decline among adults with estimated GFR $>60 \mathrm{ml} / \mathrm{min} / 1.73 \mathrm{~m}(2)$ : the Multi-Ethnic Study of Atherosclerosis (MESA). Am J Kidney Dis 2012;59:41-49.

-35 Takenaka T, Mimura T, Kanno Y, Suzuki H: Qualification of arterial stiffness as a risk factor to the progression of chronic kidney diseases. Am J Nephrol 2005;25:417-424.

-36 Taal MW, Sigrist MK, Fakis A, Fluck RJ, McIntyre CW: Markers of arterial stiffness are risk factors for progression to end-stage renal disease among patients with chronic kidney disease stages 4 and 5. Nephron Clin Pract 2007;107:c177-c181.

-37 Briet M, Boutouyrie P, Laurent S, London GM: Arterial stiffness and pulse pressure in CKD and ESRD. Kidney Int 2012;82:388-400.

-38 Loutzenhiser R, Bidani AK, Wang X: Systolic pressure and the myogenic response of the renal afferent arteriole. Acta Physiol Scand 2004;181:407-413.

39 Bidani AK, Griffin KA, Williamson G, Wang X, Loutzenhiser R: Protective importance of the myogenic response in the renal circulation. Hypertension 2009;54:393-398.

40 Griffin KA: Hypertension and kidney damage. J Clin Hypertens (Greenwich) 2006;8:209-214.

-41 Loutzenhiser R, Griffin KA, Bidani AK: Systolic blood pressure as the trigger for the renal myogenic response: protective or autoregulatory? Curr Opin Nephrol Hypertens 2006;15:41-49.

-42 Bidani AK, Polichnowski AJ, Loutzenhiser R, Griffin KA: Renal microvascular dysfunction, hypertension and CKD progression. Curr Opin Nephrol Hypertens 2013;22:1-9.

-43 Hill GS, Heudes D, Jacquot C, Gauthier E, Bariety J: Morphometric evidence for impairment of renal autoregulation in advanced essential hypertension. Kidney Int 2006;69:823-831.

44 Briet M, Bozec E, Laurent S, Fassot C, London GM, Jacquot C, Froissart M, Houillier P, Boutouyrie P: Arterial stiffness and enlargement in mild-to-moderate chronic kidney disease. Kidney Int 2006;69:350-357.

45 Lilitkarntakul P, Dhaun N, Melville V, Blackwell S, Talwar DK, Liebman B, Asai T, Pollock J, Goddard J, Webb DJ: Blood pressure and not uraemia is the major determinant of arterial stiffness and endothelial dysfunction in patients with chronic kidney disease and minimal co-morbidity. Atherosclerosis 2011;216:217-225. 